\title{
Network structure and the journey to work: An intra-metropolitan analysis
}

\author{
Pavithra Parthasarathi (corresponding author) \\ Principal Transportation Engineer \\ Hampton Roads Transportation Planning Organization \\ 723 Woodlake Drive \\ Chesapeake, VA 23320 \\ pparthasarathi@hrpdcva.gov
}

David Levinson

RP Braun-CTS Chair of Transportation

Director of Network, Economics, and Urban Systems Research Group

University of Minnesota

Department of Civil Engineering

500 Pillsbury Drive SE

Minneapolis, MN 55455 USA

dlevinson@umn.edu

http://nexus.umn.edu

Word Count: 4,879 words

Word Count incl. tables and figures: 7,129 words

July 29, 2012 


\section{ABSTRACT}

This paper aims to look at the variation of network structure within a metropolitan area and relate it to observed travel, measured here as the average travel time to work. The Minor Civil Divisions (MCD) within the Twin Cities (Minneapolis, St. Paul) metropolitan area are chosen for this analysis. Quantitative measures, compiled from various sources, are used to capture the various aspects of network structure within each MCD. The variation of these measures within the metropolitan area is analyzed using spatial analyses. The measures of network structure are then related to observed travel using statistical regression models. The results confirm a relation between network structure and travel and point to the importance of understanding the underlying street network structure. 


\section{INTRODUCTION}

There are many complex networks that exist in the world, some manmade and some natural. Examples of complex networks include the world wide web, oil pipelines, power grids, optical fibers, transport, etc. The interest in studying these networks extends across various disciplines, from neurobiology to engineering. The anatomy or structure of networks critically influences network function. For example,understanding the topology of a power grid network provides information on its robustness and stability while the topology of a social network influences the spread of information (1).

A complex network at a minimum consists of a set of nodes or vertices; these are joined together by a set of links or edges. While the basic elements of nodes and links are common among complex networks, there are fundamental differences that exist between them. In some networks the precise position of a node or vertex does not have a specific location or meaning. Examples of such networks include biochemical networks or citation network where the nodes exist only in an abstract 'network space'. On the other hand, the nodes in networks such as the world wide web have a well-defined position or location. Similarly looking at edges, the edges in certain network (street networks) have a physical presence while the edges in an aviation networks do not. Such fundamental differences between these networks point to the need for a better understanding of the underlying topology or structure (2).

The structure of transportation networks was of specific interest to geographers due to its influence on economic development. In Kansky's (3) seminal work on this topic, graph theory based measures of network structure were developed to characterize the underlying structure of transportation (railways and roadways) networks and relate it to regional economic characteristics. The research interest in understanding network structure peaked in the 1960s $(4,5,6)$. The interest tapered off in the mid-1970s shifting towards the development and application of travel demand models (7).

Recent advances in spatial analysis and modeling techniques combined with significant improvements in computing power have resulted in a revival of interest in understanding complex networks $(1,2)$. This current focus on complex networks is more on understanding the spatial or geographical aspects rather than just characterizing the topological properties of the network. The traditional focus on topology ignores the pivotal role of geography or space (8). For example, the nodal degree (number of edges connected to a node) is limited by the available physical space, specifically on planar networks like urban street networks. This in turn influences the structural properties of the network. Similarly the connections in a spatial network are a function of euclidean distance. A complete understanding of networks thus needs to includes spatial aspects such as location, distance and geography (9).

Transportation networks that connect points in geographic space easily lend themselves to spatial analysis and the interest in understanding their structural attributes hence appeals to researchers from various backgrounds. For example, physicists have now started looking at the geography and spatial aspects of transportation networks to understand and reproduce their qualitative features (2). Researchers have also used transportation networks to understand the connection patterns in real-word networks, the evolution trends in complex networks and the transferability of small-world concepts to real-world networks $(10,11,12)$.

Understanding the spatial and structural patterns of street network has numerous applications in urban planning, transportation, geovisualization and location based services (LBS) (13). The importance of understanding street network structure in the disciplines of architecture, road 
construction and urban management have been highlighted as well (14).

In the travel behavioral field, current efforts have focused on relating network structure to transportation system performance $(15,16,17)$. This paper is an extension of this research interest in network structure and travel. The variation of network structure across metropolitan areas and its influence on transportation system performance was confirmed by recent research (18). This paper looks at the variation of network structure within a metropolitan area. This variation in network structure is then related to observed travel using spatial and econometric analyses. The average travel time to work is used as a measure of observed travel. This paper is organized as follows: the next section provides a detailed explanation of the modeling methodology, namely the data, model formulation and the estimation of measures of network structure. The spatial and regression analyses are presented in the following sections. The paper concludes with a discussion of the results and its implications.

\section{MODELING METHODOLOGY}

\section{Data}

\section{Minor Civil Divisons}

The data for this analysis come from the Minor Civil Divisions (MCD) within the Twin Cities (Minneapolis, St. Paul) metropolitan area. MCDs are defined as primary divisions of a county. MCDs consists of both governmentally functioning entities, that provide services and raise revenues, and nonfunctioning entities, that exist primarily for administrative purposes. The U.S Census Bureau recognizes MCDs in twenty eight states and Puerto Rico (19).

The MCD dataset was downloaded from the MetroGIS database in GIS shape file format (20). The downloaded MCD dataset represents municipal boundaries and includes cities, townships and unorganized territories within the Twin Cities (Minneapolis, St. Paul) metropolitan area. The Twin Cities (Minneapolis, St. Paul) metropolitan area refers to the seven counties of Anoka, Carver, Dakota, Hennepin, Ramsey, Scott and Washington and includes the cities of Minneapolis and Saint Paul. There are 189 MCDs within the Twin Cities (Minneapolis, St. Paul) metropolitan area.

The area of the MCD $\left(\mathrm{km}^{2}\right)$ was estimated using ArcGIS for each MCD in the dataset. This is used as a control variable in the regression models estimated later in this paper.

\section{Street Networks}

The street network for this analysis was extracted from the U.S Census TIGER/Line files. The TIGER/line files are spatial extracts from the U.S Census Bureau's Master Address File (MAF)/ Topologically Integrated Geographic Encoding and Referencing (TIGER) database (MAF/TIGER). This database consists of select cartographic and geographic information and provides information on various features such as roads, railroads, rivers, as wells as legal and statistical geographic areas (21). The extracted Twin Cities (Minneapolis, St. Paul) network was cleaned to include just the road features based on the Feature Class Codes (FCC) for the line segments provided in the Census TIGER/Line files.

For the purposes of this current analysis, the extracted Twin Cities (Minneapolis, St. Paul) street network was overlaid on the MCD shape file to extract the street network for each MCD. These extracted street networks within each MCD were cleaned to ensure that the network contained only the relevant links and intersection or junction nodes. These networks were then used to estimate measures of network structure within each MCD, which are elaborated in a later section 
of this paper.

\section{Census Data}

The downloaded MCD dataset was supplemented with the year 2010 travel and socio-demographic data from the U.S. Census Bureau (22). The variables of interest for each MCD in the Census data include the average travel time to work and the median household income.

\section{Control Variables}

Additional data used in this paper include multimodal accessibility estimates for each MCD, which are explained below.

\section{Person weighted accessibility:}

These accessibility estimates were obtained at the Traffic Analysis Zone (TAZ) level, as part of a research project at the University of Minnesota (23). The study used accessibility estimates as a performance measure in evaluating potential land use and transportation scenarios for the Twin Cities (Minneapolis, St. Paul) metropolitan area. Cumulative accessibility to population, employment, and labor within a specified time threshold, ranging from 10 minutes to 60 minutes, were estimated for each TAZ in the Twin Cities (Minneapolis, St. Paul) metropolitan area. Additional details on the cumulative accessibility estimation are provided in related research $(23,24,25)$.

In addition to the cumulative accessibility measure, the study also provided a personweighted accessibility measure. The person-weighted accessibility for each zone, A, was estimated as the weighted average of accessibility by zone, where the weight, $W_{i}$, is the population or number of workers or jobs in that zone experiencing that level of accessibility (25).

$$
A=\frac{\sum_{i=1}^{n} A_{i} * W_{i}}{\sum_{i=1}^{n} W_{i}}
$$

This person weighted accessibility within a specific time threshold, ranging from 10 minutes to 60 minutes, can be aggregated for the entire region or any sub-region. For this analysis the aggregation was done at the MCD level by identifying the TAZs that fall within each MCD and using the TAZ's employment as weights.

The estimated person weighted accessibility to jobs using auto and transit for each MCD is used in this analysis.

\section{Analysis}

\section{Estimation of Network Measures}

The following measures of network structure were estimated using the street network structure for each MCD. The measures of network structure were designed to capture different aspects of the underlying street network and fall into the following broad categories:

- Hierarchy - refers to the differentiation that exists in street networks.

- Topology - identifies the connectivity and the connection patterns that exists in street networks.

- Scale - captures the intensity of the street network within a specified area. 
Table 1 summarizes the estimation of the above network measures, compiled from various sources. It is important to point out that many of the topology measures identified here are graphtheory based measures of network structure. Details on the estimation of these network measures is provided in (26).

A correlation test of the estimated network measures showed an extremely high correlation (almost 1.0) between the $\alpha, \beta$ and $\gamma$ measures. Refer to Table 2. An explanation for this degree of correlation between these three network measures is provided in a recent paper (27). The high correlation confirms that the three measures, estimated based on the number of links $(e)$ and number of nodes $(v)$ in the network, are essentially the same. Therefore only the $\alpha$ index will be used in the analyses presented in the following sections.

TABLE 1: Estimation of Network Measures

\begin{tabular}{|c|c|c|c|}
\hline $\begin{array}{l}\text { Network Mea- } \\
\text { sures (Unit) }\end{array}$ & Equation & Notes & Reference \\
\hline$\overline{\text { Entropy, } H(X)}$ & $-\sum_{i=1}^{m} p_{i} \log _{2}\left(p_{i}\right)$ & $\begin{array}{l}m=\text { Number of subsets in the system } X \\
p_{i}=\text { Proportion of elements in the } i^{t h} \text { subset. } \\
\text { Links are grouped here into subsets based on functional classi- } \\
\text { fication, identified using FCC codes in the Census TIGER/line } \\
\text { files. }\end{array}$ & (28) \\
\hline $\begin{array}{l}\text { Percentage } \\
\text { freeways, } \% \mathrm{~F}\end{array}$ & $\frac{L_{f}}{L_{s m}} * 100$ & $\begin{array}{l}L_{f}=\text { Length }(\mathrm{km}) \text { of the freeways within the minor civil divi- } \\
\text { sion, } \\
L_{s m}=\text { Length }(\mathrm{km}) \text { of the street network within the minor civil } \\
\text { division. }\end{array}$ & \\
\hline Alpha, $\alpha$ & $\frac{e-v+1}{2 v-5}$ & $\begin{array}{l}e=\text { Number of links or edges in the street network within the } \\
\text { minor civil division, } \\
v=\text { Number of nodes or vertices in the street network within the } \\
\text { minor civil division, } \\
e-v+1=\text { The denominator is also referred to as the cyclomatic } \\
\text { number, u, commonly used in graph theory. }\end{array}$ & (3) \\
\hline Beta, $\beta$ & $\frac{e}{v}$ & & (3) \\
\hline Gamma, $\gamma$ & $\frac{e}{3 v-6}$ & & (3) \\
\hline $\begin{array}{l}\text { Arterial Treeness, } \\
\phi_{\text {tree }}\end{array}$ & $\frac{L_{t m}}{L_{s m}}$ & $\begin{array}{l}L_{t m}=\text { Length }(\mathrm{km}) \text { of street segments belonging to a branch or } \\
\text { tree network within the minor civil division } \\
\text { Open source software }{ }^{1} \text { was used to classify each segment in } \\
\text { the street network as belonging to a tree network or a circuit } \\
\text { network. }\end{array}$ & $(5,28)$ \\
\hline
\end{tabular}

${ }^{1}$ Developed by Feng Xie, Metropolitan Washington Council of Governments (MWCOG); Code can be downloaded from http://nexus.umn.edu/Software/IdentifyingNetworkTopologies.zip 
Table 1 - continued from previous page

\begin{tabular}{|c|c|c|c|}
\hline $\begin{array}{l}\text { Network Mea- } \\
\text { sures (Unit) }\end{array}$ & Equation & Notes & Reference \\
\hline $\begin{array}{l}\text { Average Circuity, } \\
C_{t}\end{array}$ & $\frac{D_{n m}}{D_{e m}}$ & $\begin{array}{l}\mathrm{D}_{n m}=\text { Sum of the network distance }(\mathrm{km}) \text { between all OD pairs } \\
\text { in the minor civil division, } \\
\mathrm{D}_{e m}=\text { Sum of the euclidean distance }(\mathrm{km}) \text { between all OD pairs } \\
\text { in the minor civil division. }\end{array}$ & $(29,30)$ \\
\hline Eta, $\eta(k m)$ & $\frac{L_{s m}}{e}$ & & (3) \\
\hline Theta, $\theta(\mathrm{km})$ & $\frac{T_{m}}{v}$ & $\begin{array}{l}T_{m}=\text { Total traffic within the minor civil division, measured here } \\
\text { as Daily Vehicle Kilometers Traveled (DVKT) }\end{array}$ & (3) \\
\hline $\begin{array}{l}\text { Street density, } \\
\rho_{l m}(1 / \mathrm{km})\end{array}$ & $\frac{L_{s m}}{A_{m}}$ & $A_{m}=$ Area $\left(\mathrm{km}^{2}\right)$ of the minor civil division. & \\
\hline
\end{tabular}




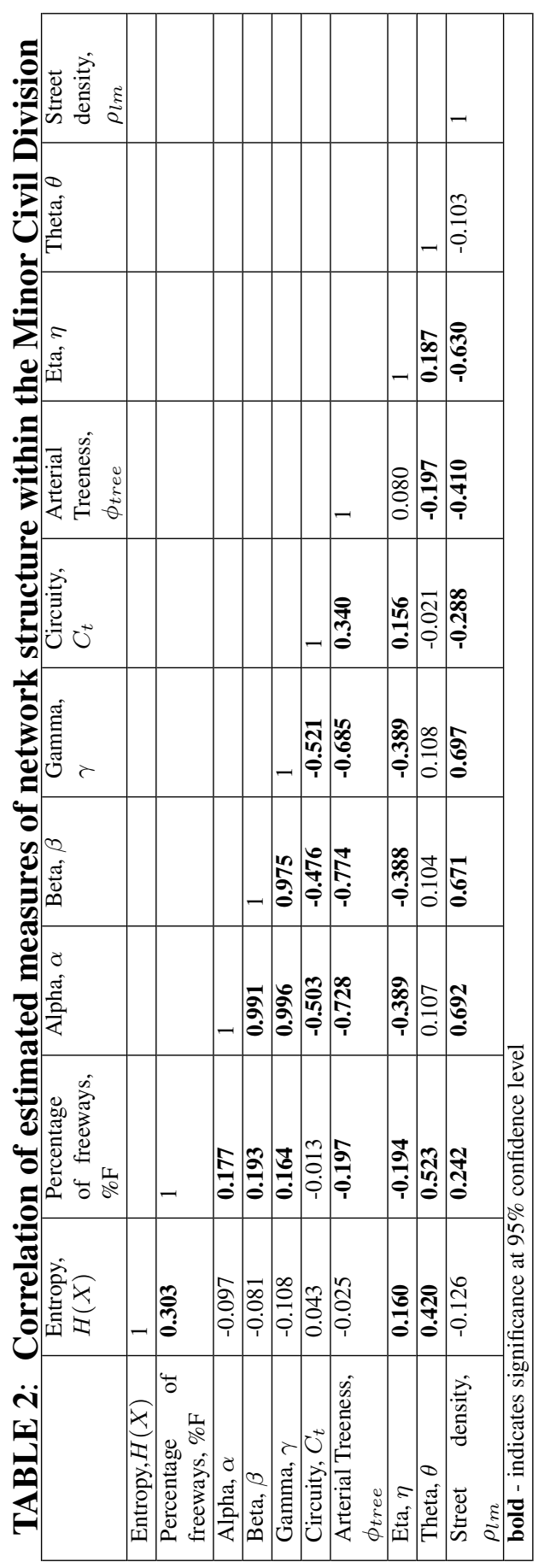




\section{Spatial Analysis}

The objective of this paper was to analyze the variation of network structure within a metropolitan area and relate this variation to observed travel. The MCDs within the Twin Cities (Minneapolis, St. Paul) metropolitan area were chosen for this analysis. The first step in this analysis was to look at the spatial variation of the network structure across the MCDs, as presented in figures 1(a) through 1(e). To better understand the spatial variation, the circumferential limited access highway, also called the I-494/I-694 beltway, around the central portion of the Twin Cities (Minneapolis, St. Paul) metropolitan area and the cities of Minneapolis and St. Paul are identified in each of the figures.

Consider the variation of the estimated $\alpha$ index, shown in figure 1(a). As pointed out previously, the $\alpha$ index measures the degree of connectivity within the street network. The $\alpha$ index varies between 0 and 1 and a higher value of the $\alpha$ index indicates higher connectivity in the network. From figure 1(a), we can see a clear pattern emerge across the metropolitan area. The $\alpha$ index is highest in the center of the Twin Cities (Minneapolis, St. Paul) metropolitan area within the I-494/I-694 beltway and the value progressively decreases as we move out towards the edge. The street networks in the central part of the metropolitan area (includes the cities of Minneapolis and St.Paul), have a typical, though imperfect grid-like structure and therefore show a higher $\alpha$ index. The outer part of the metropolitan area typically has a meandering tree like network which corresponds to the lower value of the $\alpha$ index.

The spatial variation of the $\phi_{\text {tree }}$ measure is presented in figure $1(\mathrm{~b})$. The variation of $\phi_{\text {tree }}$ shows that the grid networks in the central part of the metropolitan area have a lower $\phi_{\text {tree }}$ value. The outer edge of the metropolitan area show higher $\phi_{\text {tree }}$ values. Now look at the corresponding variation of $C_{t}$ measure shown in figure 1(c). Like the $\phi_{\text {tree }}$ measure, the lowest $C_{t}$ value is seen in the central cities of Minneapolis and St. Paul and the highest $C_{t}$ value is seen in the MCDs on the outer edge of the metropolitan area. This variation in $\phi_{\text {tree }}$ and $C_{t}$ measures confirm that the grid network, with a lower proportion of tree-like segments, provide more direct routes for travelers, resulting in lower $C_{t}$ values. On the other hand, suburban networks with a higher proportion of tree-like segments, provide less direct routes for travelers, resulting in higher $C_{t}$ values.

Now consider the spatial variation of the $\eta$ index presented in figure 1(d). As explained previously, the $\eta$ index measures the average link or edge length. Figure 1(d) shows that the $\eta$ value progressively increases from the central part of the metropolitan area towards the outer edge of the metropolitan area. The central cities of Minneapolis and St. Paul have the lowest $\eta$ value. This shows that the average edge length is lower for grid-like street networks compared to treelike street networks. The variation in the $\eta$ index corresponds to the variation in $\rho_{l m}$, presented in figure 1(e). The $\rho_{l m}$ variable captures the intensity of the street network within a given area and is highest in the central part of the metropolitan area and progressively decreases towards the outer edge of the metropolitan area.

The estimated network measures presented in Figures 1(a) through 1(e) show the spatial variation across MCDs in the metropolitan area. The spatial analysis confirms the difference in network structure between the grid-like street networks seen in the central portion of the Twin Cities (Minneapolis, St. Paul) metropolitan area and the tree-like street networks seen in the outer edges of the metropolitan area. The estimated network measures help quantify the differences in street network structure across the metropolitan area.

The spatial analysis also point to a relationship between certain network measures. To expand on this, scatterplots of select network measures were analyzed and are presented in fig- 
ures 2(a) through 2(e). Consider the relationship between the $\alpha$ index and $C_{t}$ measure presented in figure 2(b). This scatterplot shows that the circuity in the network decreases with increased connectivity as measured by the $\alpha$ index. Similarly the treeness in the network decreases with increased connectivity, as seen in the scatterplots of figure 2(c). Another scatterplot comparison between the $\theta$ index and the $H(X)$ index is presented in figure 2(f). The scatterplot shows a positive relationship between the two variables in that the traffic load of the network, measured by $\theta$ increases with increasing $H(X)$. Please note that the scatterplots presented here highlight specific relationships between select network variables and do not cover all variables estimated in Table 1. 


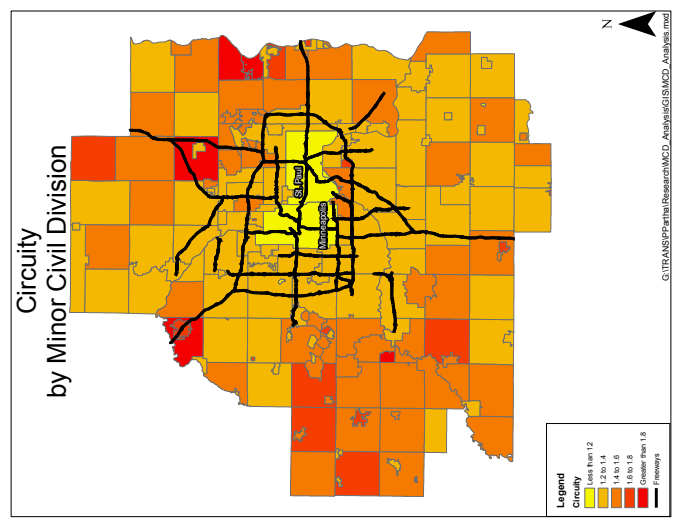

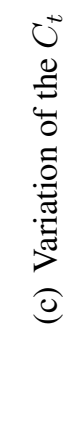
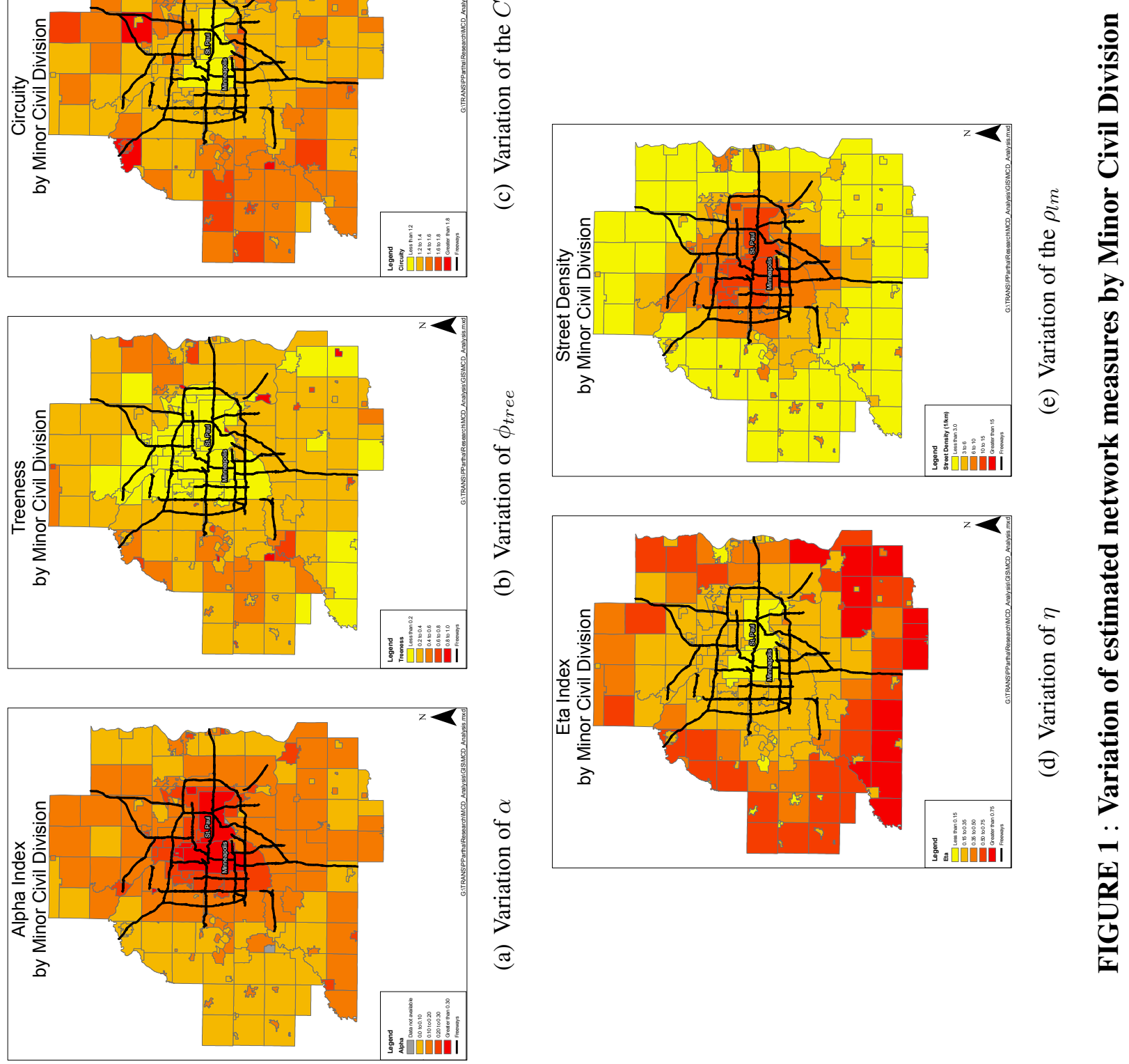

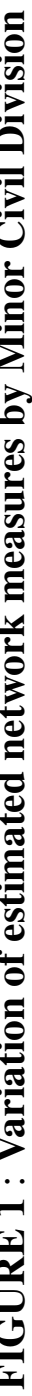



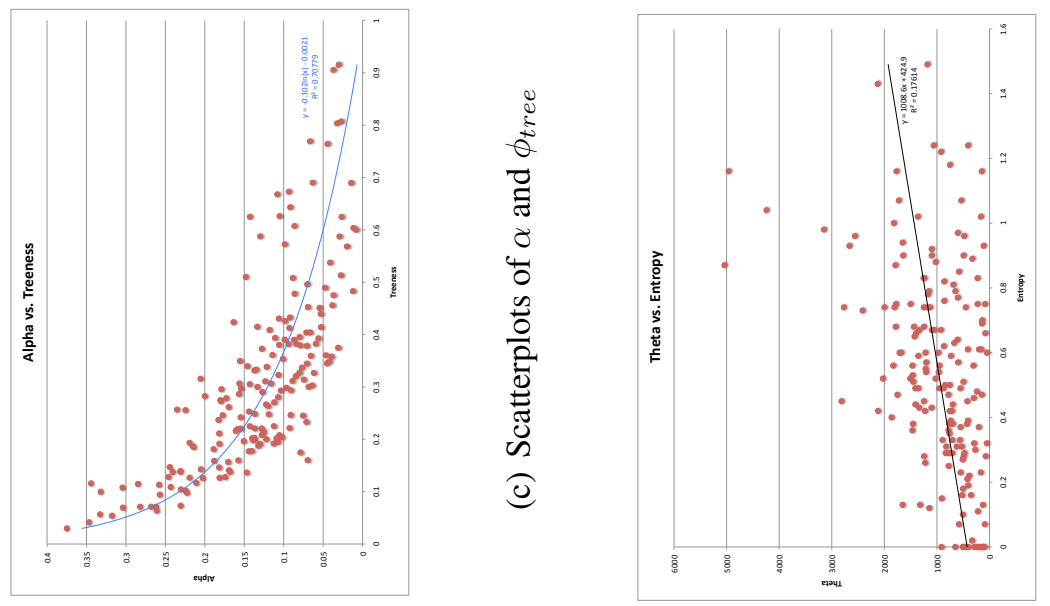

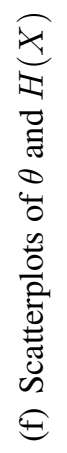
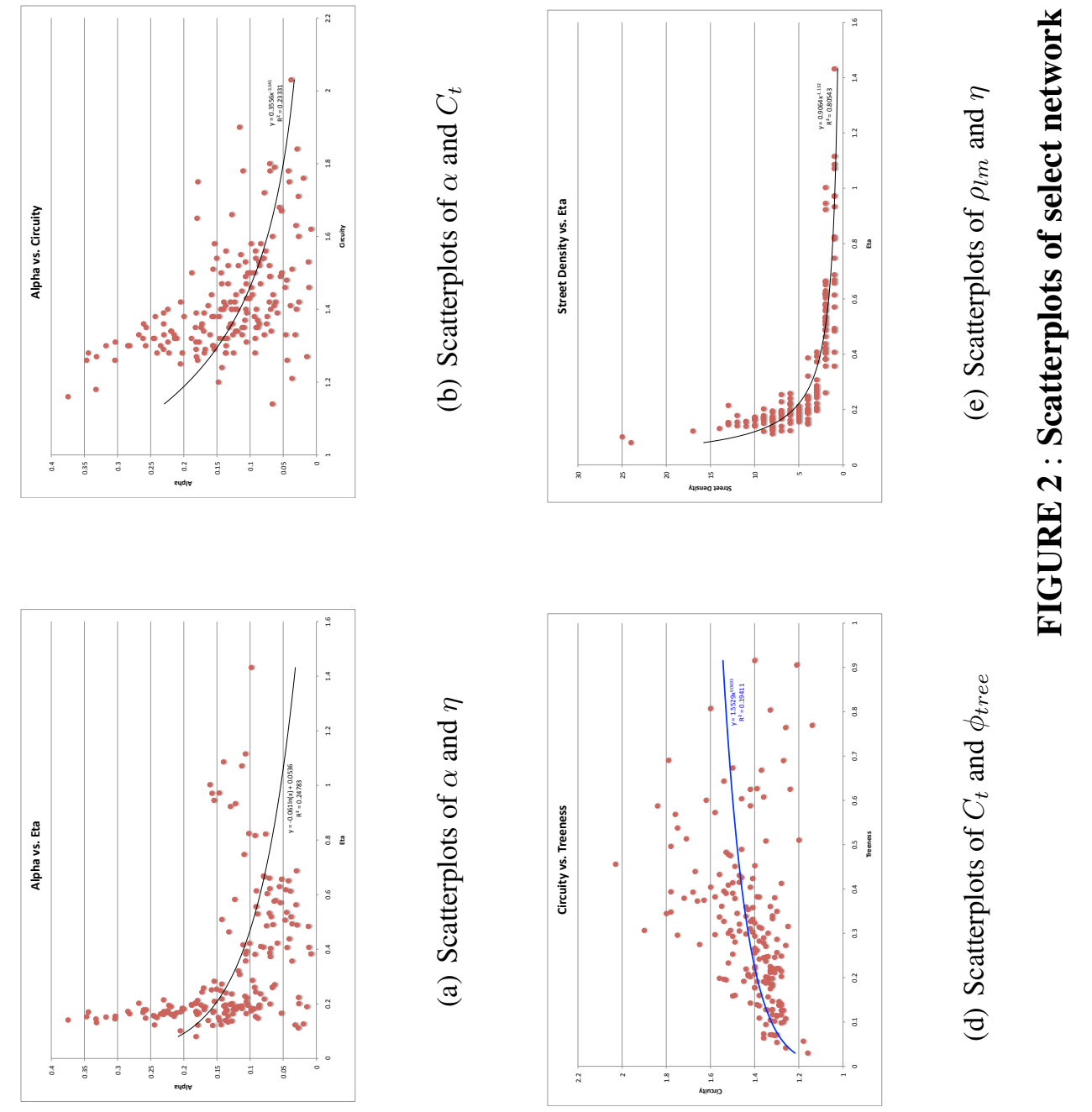


\section{Regression analysis}

The analyses in the previous section shows the spatial variation of estimated network measures within the metropolitan area and also highlight specific relationships between select network measures. The analysis in this section relates the estimated network measures within the MCD to observed travel using statistical regression models. The 2010 average travel time to work in minutes from the U.S Census Bureau is used as a measure of observed travel for each MCD.

\section{Categorical Analysis}

Before getting into the estimation of the statistical model, a simple categorical analysis of the relation between the estimated network measures and observed travel was conducted. The MCDs in the metropolitan area were grouped into four categories based on the average travel time to work, as listed below:

- Category 1 - Average travel time less than 20 minutes

- Category 2 - Average travel time between 21 minutes and 25 minutes

- Category 3 - Average travel time less than 25 minutes and 30 minutes

- Category 4 - Average travel time greater than 30 minutes

The mean value of the network measures, listed in Table 1, was calculated for each of the above listed time categories. These values are tabulated in Table 3 and show interesting patterns. For example, consider the mean value of $H(X)$, which measures the differentiation in the street network. The tabulation shows that the entropy, $H(X)$, is highest for category 1 (travel time to work is less than 20 minutes) and lowest for category 4 (travel time to work is greater than 30 minutes). As explained in table 1, a higher entropy value indicates the presence of higher functional classification links in the network such as arterials compared to local streets. The higher functional classification links are typically faster and result in lesser travel time. Similarly the treeness variable, $\phi_{\text {tree }}$, which measures the presence of tree-like segments, is lowest for category 1 and is the highest for category 4. A tree-like network provides minimum connections and hence longer distances between the fixed origins and destinations and thus results in higher travel time. These kind of patterns are consistently seen in all network variables with the exception of $\eta$ index and circuity, $C_{t}$.

\section{Regression models}

The categorical tabulations show a relation between measures of street network structure and observed travel. The next step was to quantify this relation using statistical regression models. Based on the above spatial and scatterplot analyses, a set of core hypotheses were formulated for the various network measures listed in Table 1. These hypotheses are listed below:

- Hypothesis 1 - Aspects of network structure that increase the connectivity of the street network within a MCD (operational variables $-\alpha$ ) will decrease the average travel time to work.

- Hypothesis 2 - Aspects of network structure that increase the network travel distance (operational variables - $\phi_{\text {tree }}, C_{t}$ ) between fixed origins and destinations within a MCD will increase the average travel time to work. 
TABLE 3: Mean values of estimated network measures by travel time category

\begin{tabular}{|l|l|l|l|l|}
\hline & \multicolumn{4}{|c|}{ Average travel time (minute) to work category } \\
\hline & Category 1 & Category 2 & Category 3 & Category 4 \\
\hline $\begin{array}{l}\text { Independent vari- } \\
\text { ables (Unit) }\end{array}$ & $\begin{array}{l}\text { Less than 20 } \\
\text { mins }\end{array}$ & $\begin{array}{l}\text { Between } \\
21 \text { and 25 } \\
\text { minutes }\end{array}$ & $\begin{array}{l}\text { Between } \\
25 \text { and 30 } \\
\text { minutes }\end{array}$ & $\begin{array}{l}\text { Greater than } \\
\text { 30 minutes }\end{array}$ \\
\hline Entropy, $H(X)$ & 0.77 & 0.55 & 0.52 & 0.39 \\
\hline $\begin{array}{l}\text { Percentage of free- } \\
\text { ways, \%F }\end{array}$ & 4.37 & 2.20 & 0.73 & 0.00 \\
\hline Alpha, $\alpha$ & 0.17 & 0.16 & 0.10 & 0.10 \\
\hline $\begin{array}{l}\text { Arterial Treeness, } \\
\phi_{\text {tree }}\end{array}$ & 0.21 & 0.26 & 0.34 & 0.42 \\
\hline $\begin{array}{l}\text { Average Circuity, } \\
C_{t}\end{array}$ & 1.41 & 1.37 & 1.48 & 1.44 \\
\hline Eta, $\eta$ & 0.21 & 0.25 & 0.42 & 0.39 \\
\hline Theta, $\theta$ & 1735.57 & 1047.80 & 920.29 & 476.29 \\
\hline $\begin{array}{l}\text { Street Density, } \rho_{l m} \\
\left(k m^{-1}\right)\end{array}$ & 7.50 & 7.15 & 3.47 & 3.46 \\
\hline
\end{tabular}

- Hypothesis 3 - Aspects of network structure which increase the differentiation in the street network (operational variables: $H(X), \% \mathrm{~F}$ ) within a MCD will reduce the average travel time to work. These measures capture the presence of higher hierarchy links such as interstates, which typically have higher speeds and reduce travel time.

- Hypothesis 4 - An increase in the MCD's person-weighted accessibility to jobs within a time threshold (30 minutes here) by auto or transit $\left(A_{30}, O_{30}\right)$ lowers the need for longer travel and reduces the average travel time to work.

It is important to note that while the above set of the hypotheses includes a broad set of network measures, the estimated models include only select network measures. Each of the independent network variables were included sequentially in the models based on the estimated correlation between the network variables and the statistical significance of each of the variables.

The estimated models predict the average travel time to work as a function of the independent network variables. Various formulations of the proposed model were analyzed and the results of three select models are presented here. The multimodal (auto, transit) person weighted accessibility to jobs within a 30 minute time threshold $\left(A_{30}, T_{30}\right)$, the median household income and the size of the minor civil division were used as control variables in all three models. The first model is a linear regression model with the dependent variable and all independent variables in linear form. The second model is a log model similar to the linear regression model but with the dependent variable and all independent variables in natural log form. The third model is a factor analysis model.

The results presented from the linear and log regression models in Table 6 show the influence of select network structure variables, after accounting for the control variables. The entropy variable, $H(X)$, has a significant negative influence on the average travel time. This result is consistent with our hypothesis that an increase in network hierarchy will decrease the travel time. Similarly an increase in the average circuity, $C_{t}$, in the network increases the average travel time 
TABLE 4: Rotated Factor Loadings

\begin{tabular}{|c|c|c|c|c|}
\hline Independent Variables & $\begin{array}{l}\text { Factor } 1- \\
\text { Topology } \\
\text { Factor }\end{array}$ & $\begin{array}{l}\text { Factor } 2- \\
\text { Hierarchy } \\
\text { Factor }\end{array}$ & $\begin{array}{l}\text { Factor } 3- \\
\text { Scale Factor }\end{array}$ & $\begin{array}{l}\text { Factor } 4- \\
\text { Accessibil- } \\
\text { ity Factor }\end{array}$ \\
\hline Entropy, $H(X)$ & & 0.699 & & \\
\hline Percentage of freeways, $\% \mathrm{~F}$ & & 0.801 & 0.352 & \\
\hline Alpha, $\alpha$ & -0.846 & & 0.402 & \\
\hline Arterial Treeness, $\phi_{\text {tree }}$ & 0.839 & & & \\
\hline Average Circuity, $C_{t}$ & 0.731 & & & \\
\hline Eta, $\eta$ & & & -0.910 & \\
\hline Theta, $\theta$ & & 0.826 & & \\
\hline Street Density, $\rho_{l m}$ & -0.457 & & 0.785 & \\
\hline $\begin{array}{l}\text { Person weighted accessibility to } \\
\text { jobs by auto, } A_{30}\end{array}$ & & & & 0.899 \\
\hline $\begin{array}{l}\text { Person weighted accessibility to } \\
\text { jobs by transit, } T_{30}\end{array}$ & & & & 0.899 \\
\hline \multicolumn{5}{|c|}{ Only loadings with absolute values greater than 0.3 presented } \\
\hline \multicolumn{5}{|c|}{ Loadings represent correlations between independent variables and identified factors } \\
\hline \multicolumn{5}{|c|}{ Factor 1 consists primarily of the $\alpha, \phi_{t r e e}$ and $C_{t}$ variables. Referred to as the topology factor } \\
\hline \multicolumn{5}{|c|}{ Factor 2 consists of the $H(X), \% \mathrm{~F}$ and $\theta$ variables. Referred to as the hierarchy factor } \\
\hline \multicolumn{5}{|c|}{ Factor 3 consists of the $\eta$ and $\rho_{l m}$ variables. Referred to as the scale factor } \\
\hline
\end{tabular}

to work. These findings are consistent in both the linear and log regression models. The other variables of network structure were included in these models but did not show up as statistically significant or were not included due to their correlation with other independent variables.

Now coming to the factor analysis model - factor analysis is a statistical technique that is used to uncover relationships among numerous variables. This technique is used to reduce a large number of correlated independent variables into smaller dimensions, called factors (31). In this analysis, the factor analysis technique was used to reduce the independent network structure variables into three relevant factors, namely, topology factor, hierarchy factor and scale factor.

In addition to the network factors, the person weighted accessibility to jobs by auto and transit $\left(A_{30}, T_{30}\right)$ were reduced to a single relevant accessibility factor. The rotated factor loadings of the network variables and accessibility variables are provided in Table 4. The three network factors and the accessibility factor were then used as independent variables in the model along with the median household income and the size of the minor civil division to predict the average travel time to work.

The pattern of influence of the factors are based on the underlying variables that make up the factor. For example, the accessibility factor primarily consists of two variables, namely, $A_{30}$ and $T_{30}$. Based on the hypotheses listed above, both these variables have a negative influence on the travel time to work. Hence the accessibility factor would have a negative influence on travel time as well and this is confirmed by the results presented in Table 6. The topology factor has the expected positive influence on the average travel time to work but is however not significant. The hierarchy factor has the expected significant negative influence while the scale factor has a significant positive influence. 
The models presented in Table 6 confirm that the network variables influence the travel time to work, after accounting for non-network control variables. The use of different model formulations was to see if the influence of the network variables changes with the model structure. The results show a consistent pattern of influence across the models.

While only select variables were included in the regression models, the results show a relation between certain aspects of network structure and travel. The regression results along with the other analyses (spatial, scatterplot, categorical) point to the importance of considering underlying network structure in understanding travel. The findings in this paper are consistent with a broader research effort (26) that looked at the influence of network structure on individual, household and metropolitan travel.

On another note, the inclusion of the person weighted accessibility to jobs by auto and transit $\left(A_{30}, T_{30}\right)$ has the most significant influence on model performance, as measured by higher $R^{2}$. The importance of using accessibility as an approach to understand the transportation system performance and the interaction of land use and transportation has been highlighted in recent research $(18,32,33)$. The analysis presented here confirms similar importance of the accessibility measure in transportation system performance (12).

How can these results be applied? At a simple level, consider the log regression model presented in Table 6. The structure of the log model is such that the regression coefficient serve as elasticity estimates. The estimates measure the percent change in the dependent variable, due to an one percent change in the independent variable. A $1 \%$ increase in the entropy, $H(X)$, of the street network reduces the average travel time to work by $0.044 \%$. Similarly a $1 \%$ increase in the average circuity, $C_{t}$, results in a $0.149 \%$ increase in the average travel time to work. Looking at accessibility - a $1 \%$ increase in the person weighted accessibility to jobs by auto, $A_{30}$, results in a $0.147 \%$ decrease in the average travel time to work. These elasticity estimates in itself are small in magnitude. However what the results point to is that a combination of these network measures along with other conventional measures of urban form and the built environment can be used to bring about desired changes in travel.

Now consider the street networks of four select MCDs from the Twin Cities (Minneapolis, St. Paul) region, presented in figure 2. In a paper on network circuity, Levinson and El-Geneidy (30) divided the Twin Cities region into four distinct rings. The first ring (ring 1) refers to the urban core that includes the cities of Minneapolis and St. Paul. Ring 2 refers to area outside the urban area but within the I-494/I-694 beltway. Ring 3 refers to the area just outside the I-494/I-694 beltway while Ring 4 refers to the outlying areas of the region. Using the same approach, the city of Minneapolis is part of the urban core (Ring 1) of the region. The city of Golden Valley lies within Ring 2. The City of Woodbury lies within Ring 3 while the City of Forest Lake belongs to Ring 4. Each of these MCDs have a different connection pattern. Each connection pattern results in a different network structure that in turn results in varying system performance. Table 5 confirms the same.

\section{CONCLUSIONS}

The objective of this paper was to analyze the spatial variation of street network structure across MCDs within the Twin Cities (Minneapolis, St. Paul) metropolitan area and relate it to observed travel. Measures to quantify the street network structure were compiled from existing sources. The spatial variation of network structure across the metropolitan area was analyzed using GIS. Further expanding the spatial analysis, the relationship between specific network measures were analyzed 
using scatterplots. Finally the relationship between the network measures and observed travel was analyzed using categorical analysis and statistical regression models.

The analyses confirm that there is an inherent variation in the street network structure within a metropolitan area. More specifically the underlying structure of the traditional grid-like networks seen in the central cities of the metropolitan area differs from the structure of the tree-like street networks seen towards the outer edge of the metropolitan area. Further the analyses confirms that these differences in underlying street network structure translates into differences in observed travel. The influence of the network measures remain significant, even after controlling for independent non-network variables.

This analysis quantifies network design and its influence on travel. This understanding of network design is valuable, especially in developing countries where new transportation system are rapidly being built. The transportation sector is the biggest consumer of energy and one of the biggest sources of greenhouse gas (GHG) emissions. Further transportation network decisions are largely irreversible. Therefore it is critical that network architecture be well understood and considered in the design of urban form and sustainable environments.

TABLE 5: Estimated street network measures and performance for select MCDs

\begin{tabular}{|l|l|l|l|l|}
\hline & Ring 1 & Ring 2 & Ring 3 & Ring 4 \\
\hline & Minneapolis & Golden Valley & Woodbury & Forest Lake \\
\hline Nodes, $v$ & 7582 & 1003 & 1852 & 722 \\
\hline Links, $e$ & 13,264 & 1463 & 2303 & 927 \\
\hline Entropy, $H(X)$ & 0.53 & 0.75 & 0.43 & 0.92 \\
\hline $\begin{array}{l}\text { Percentage of free- } \\
\text { ways, \%F }\end{array}$ & 2.82 & 5.78 & 3.0 & 3.4 \\
\hline Alpha, $\alpha \quad$ Treeness, & 0.03 & 0.23 & 0.12 & 0.14 \\
\hline $\begin{array}{l}\text { Arterial } \\
\phi_{\text {tree }}\end{array}$ & 0.10 & 0.20 & 0.31 \\
\hline Average Circuity, $C_{t}$ & 1.16 & 1.33 & 1.34 & 1.47 \\
\hline Eta, $\eta$ & 0.14 & 0.17 & 0.19 & 0.27 \\
\hline Theta, $\theta$ & 1463.46 & 1779.39 & 1103.87 & 1100 \\
\hline $\begin{array}{l}\text { Street Density, } \rho_{l m} \\
\left(k m^{-1}\right)\end{array}$ & 12 & 9 & 5 & 3 \\
\hline $\begin{array}{l}\text { Average travel time to } \\
\text { work }\end{array}$ & 22.1 & 19.1 & 25.4 & 29.7 \\
\hline
\end{tabular}



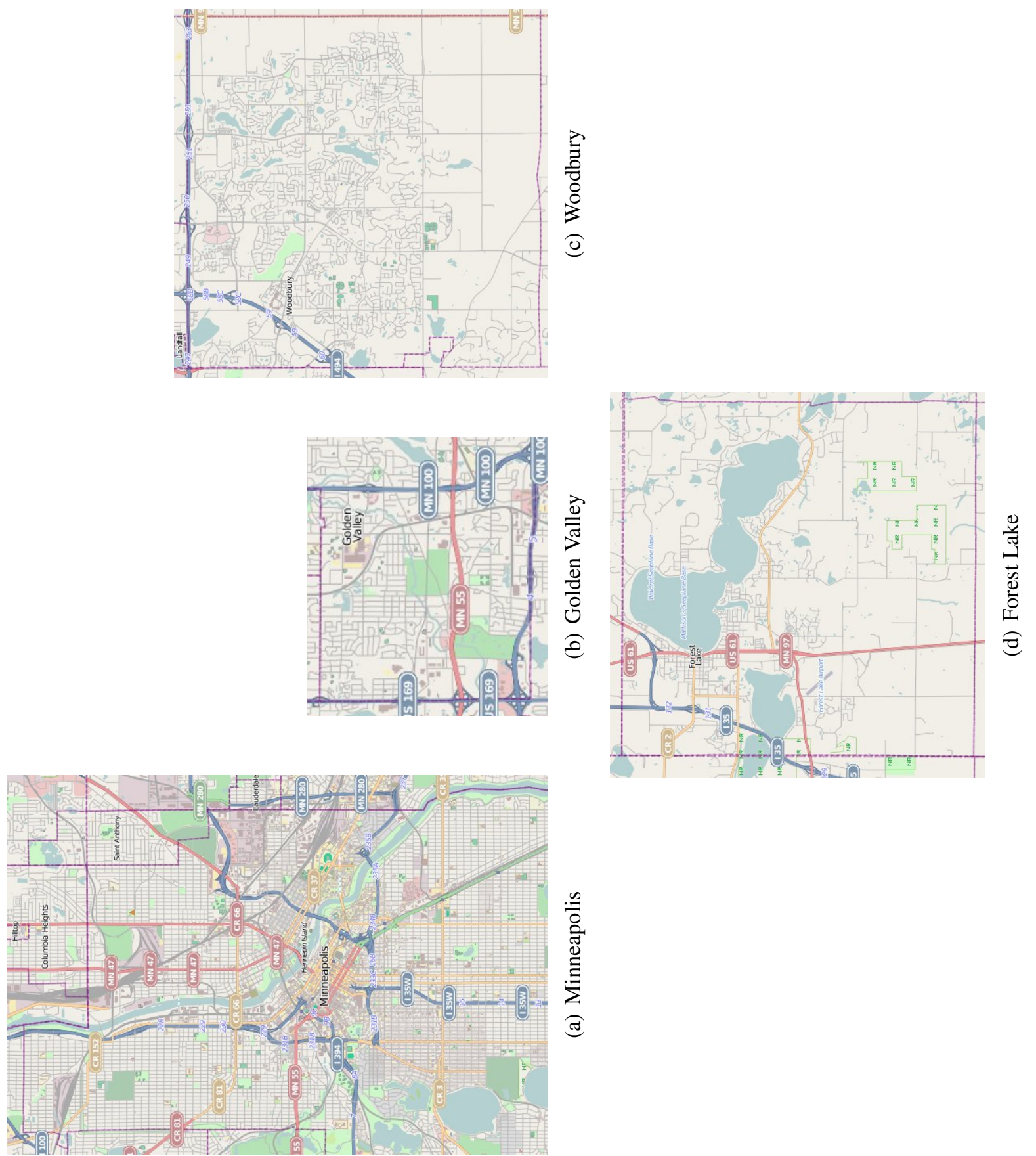

•⿹弋日 


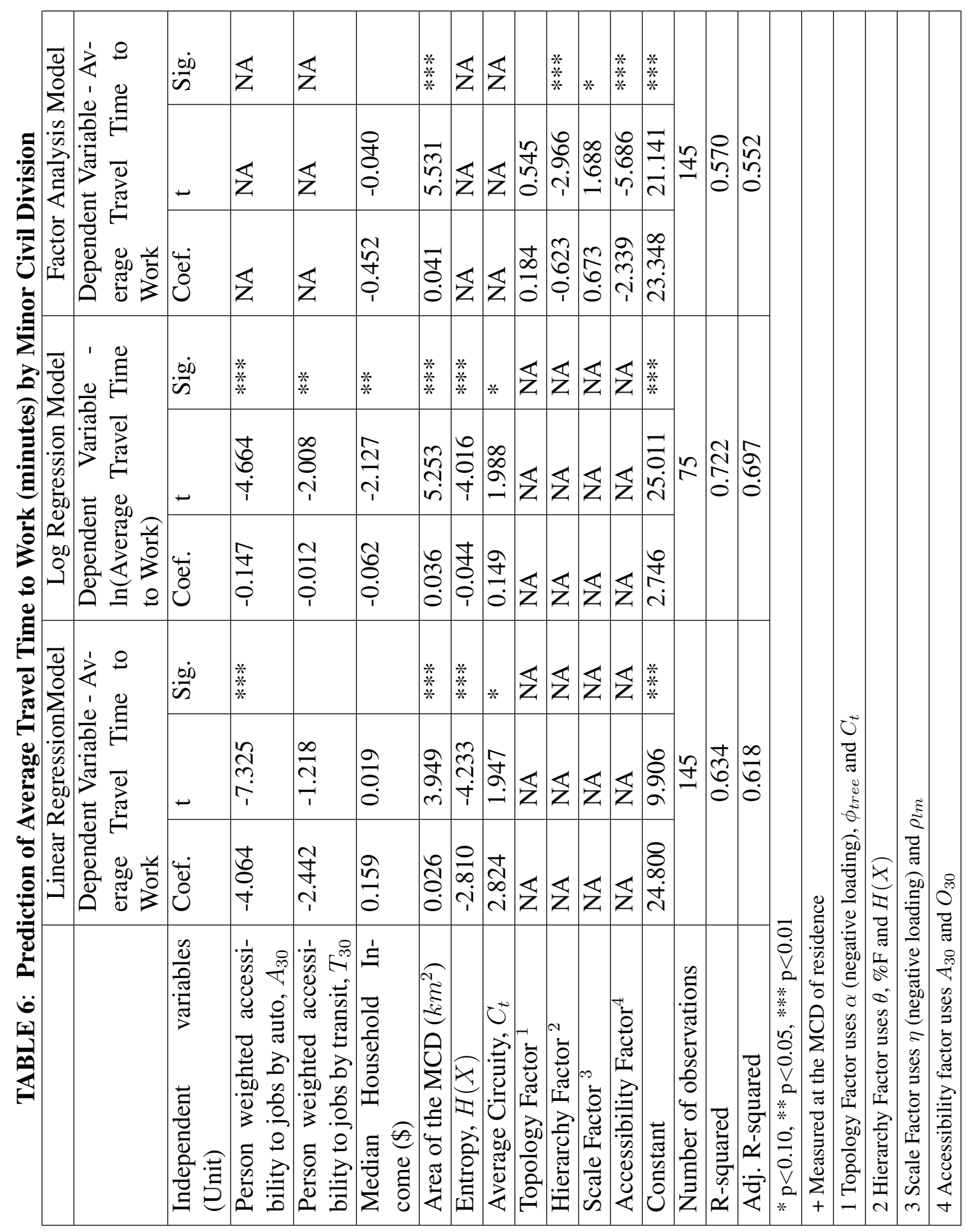




\section{REFERENCES}

[1] S. Strogatz, "Exploring complex networks," Nature, vol. 410, no. 6825, pp. 268-276, 2001.

[2] M. Gastner and M. Newman, "The spatial structure of networks," The European Physical Journal B-Condensed Matter and Complex Systems, vol. 49, no. 2, pp. 247-252, 2006.

[3] K. Kansky, Structure of Transportation Networks: Relationships Between Network Geometry and Regional Characteristics. PhD thesis, University of Chicago, 1963. Research Paper No. 84.

[4] W. L. Garrison and D. F. Marble, The structure of transportation networks. Evanston, Ill.: Transportation Center at Northwestern University, 1961. Draft of a report submitted October 31, 1961 to U.S. Army Transportation Research Command, Fort Eustis, Virginia, by the Transportation Center at Northwestern University under contract DA-44-177-TC-685, Transportation geography study.

[5] P. Haggett and R. Chorley, Network analysis in Geography. London, U.K: Edward Arnold, 1969.

[6] E. Taaffe and H. Gauthier Jr., Geography of Transportation. Englewood Cliffs, NJ: PrenticeHall, 1973.

[7] S. Derrible and C. Kennedy, "A network analysis of subway systems in the world using updated graph theory," Transportation Research Record, vol. 2112, pp. 17-25, 2009.

[8] S. Boccaletti, V. Latora, Y. Moreno, M. Chavez, and D. Hwang, "Complex networks: Structure and dynamics," Physics reports, vol. 424, no. 4, pp. 175-308, 2006.

[9] S. Gorman and R. Kulkarni, "Spatial small worlds: new geographic patterns for an information economy," Environment and Planning B, vol. 31, no. 2, pp. 273-296, 2004.

[10] V. Latora and M. Marchiori, "Is the boston subway a small-world network?," Physica A: Statistical Mechanics and its Applications, vol. 314, no. 1, pp. 109-113, 2002.

[11] R. Guimerà, M. Sales-Pardo, and L. Amaral, "Classes of complex networks defined by roleto-role connectivity profiles," Nature physics, vol. 3, no. 1, pp. 63-69, 2006.

[12] S. Derrible, "Network centrality of metro systems," PLoS ONE, vol. 7, no. 7, p. e40575, 2012.

[13] B. Yang, X. Luan, and Q. Li, "An adaptive method for identifying the spatial patterns in road networks," Computers, Environment and Urban Systems, vol. 34, pp. 40-48, 2009.

[14] S. Marshall, Streets \& Patterns. Spon New York, 2005.

[15] S. Derrible, The Properties and Effects of Metro Network Designs. PhD thesis, Department of Civil Engineering, University of Toronto, 2010. 
[16] E. Jenelius, "Network structure and travel patterns: Explaining the geographical disparities of road network vulnerability," Journal of Transport Geography, vol. 17, no. 3, pp. 234-244, 2009.

[17] B. Jiang, J. Yin, and S. Zhao, "Characterizing the human mobility pattern in a large street network," Physical Review E, vol. 80, no. 2, 2009.

[18] P. Parthasarathi and D. Levinson, "Network Structure and Metropolitan Mobility," in 90th Annual Meeting of the Transportation Research Board, (Washington, D.C), January 2011.

[19] U.S. Census Bureau, "About Population Estimates, Geographic Terms and Definitions." http://www.census.gov/popest/about/geo/terms.html, December 2011.

[20] MetroGIS DataFinder, "Minor Civil Divisions.” www.datafinder.org, April 2011.

[21] U.S. Census Bureau, “Topologically Integrated Geographic Encoding and Referencing system (TIGER) Overview.” http://www.census.gov/geo/www/tiger, August 2008.

[22] U.S. Census Bureau, “American Community Survey, 2010." Accessed at http://mcdc2.missouri.edu/cgi-bin/uexplore?/pub/data/acs2010, 2010.

[23] P. Anderson, D. Levinson, and P. Parthasarathi, “Accessibility futures.” Working Paper, 2011.

[24] A. M. El-Geneidy and D. M. Levinson, Access to destinations : development of accessibility measures. No. 1, St. Paul, Minn.; Springfield, Va.: Minnesota Department of Transportation, Research Services Section ; Available through the National Technical Information Service, 2006. Access to destinations study report.

[25] D. Levinson, B. Marion, and M. Iacono, "Access to destinations, Phase 3: Measuring accessibility by automobile," Tech. Rep. 11, Minnesota Department of Transportation, March 2010 .

[26] P. Parthasarathi, Network Structure and Travel. PhD thesis, Department of Civil Engineering, University of Minnesota, 2011.

[27] D. Levinson, "Network structure and city size," PloS one, vol. 7, no. 1, p. e29721, 2012.

[28] F. Xie and D. Levinson, "Measuring the structure of road networks," Geographical Analysis, vol. 39, no. 3, pp. 336-356, 2007.

[29] R. Ballou, H. Rahardja, and N. Sakai, "Selected country circuity factors for road travel distance estimation," Transportation Research Part A, vol. 36, no. 9, pp. 843-848, 2002.

[30] D. Levinson and A. El-Geneidy, "The minimum circuity frontier and the journey to work," Regional Science and Urban Economics, vol. 39, no. 6, pp. 732-738, 2009.

[31] D. Stanek, "Modeling perceptions and preference of home-based and center-based telecommuting.," Master's thesis, Department of Civil and Environmental Engineering, University of California, Davis, December 1995. 
[32] D. Levinson, "Accessibility and the journey to work," Journal of Transport Geography, vol. 6, no. 1, pp. 11-21, 1998.

[33] D. Levinson and K. Krizek, Access to destinations. Elsevier, 2005. 